\section{Gene Therapy in Epilepsy}

\author{
Annamaria Vezzani, Ph.D.
}

Mario Negri Institute for Pharmacological Research, Milan, Italy

The generation of viral vectors, such as adeno-associated virus $(A A V)$ and lentivirus, which are capable of stable transduction of neurons, offers an attractive strategy for introducing novel genes into the brain, resulting in a long-lasting production of specific proteins. An alternative approach to achieving transgene expression in brain is to graft cells that are genetically engineered to produce neuroactive substances. Neuroactive peptides, adenosine, and $\gamma$ aminobutyric acid, are agents that can be delivered by gene and cell therapy with potential utility in epilepsy therapy.

\section{Viral Vectors for Gene Transfer}

Viral vectors, in conjunction with other methods of in vivo gene transfer, are novel tools for studying the function of genes in the mammalian central nervous system (CNS). Moreover, such gene-transfer approaches can induce the expression of "therapeutic" molecules, providing potential opportunities for treating some CNS diseases. Neurotropic viral vectors can express single or multiple foreign genes as well as a wide variety of regulatory elements and can be engineered at either or both the capsid and promoter level to provide highly targeted, cell-specific gene transfer. Neurotropic viral vectors also permit short-term or long-term CNS transgene expression to be achieved in different regions of the brain through stereotaxic delivery.

Various viral vectors, including herpes simplex virus, adenoviruses, and retroviruses, have been developed for gene therapy $(1,2)$. The adeno-associated virus (AAV) vector system appears to have several advantages for gene transfer over the other virus vectors, including a high efficiency of infection and minimal induction of host immune and inflammatory responses $(3,4)$. The efficacy of the AAV system is based on its ability to package any DNA up to a size limit of $\sim 4.5 \mathrm{~kb}$ (5). The AAV vectors

Address correspondence to Annamaria Vezzani, Ph.D., Mario Negri Institute for Pharmacological Research, Via Eritrea, Milan, 20157, Italy. E-mail: vezzani@marionegri.it

Epilepsy Currents, Vol. 4, No. 3 (May/June) 2004 pp. 87-90

Blackwell Publishing, Inc.

(c) American Epilepsy Society are nonpathogenic in that they lack the machinery for virus replication, and consequently, infection will be limited to the site of injection. $A A V s$ are very promiscuous and infect virtually all cell types in a variety of host organisms; therefore to restrict gene expression to specific cell types, the use of a tissue-specific (i.e., cell-specific) promoter is needed.

Harmful recombination events, such as insertional mutagenesis or reversion to wild type, are a general problem that may occur with viral vectors, particularly when pathogenic viruses are modified for gene transfer. Because of replication initiator protein (Rep) deletion, recombinant AAV (rAAV) is believed to exist mainly in episomal form, with variable levels of integration in nondividing cells. Nonspecific host effects on the virus activity, such as promoter silencing or immunologic reactions, are another issue of concern with the use of viral vectors. Integrated rAAVs have not been reported to have any mutagenic or deleterious effects; however, high-dose vascular delivery could be tumorigenic (6), thus warranting further long-term studies.

\section{Gene Transfer in Seizure Disorders: The Choice of "Therapeutic" Genes}

An imbalance in excitatory and inhibitory neurotransmission is a widely recognized hypothesis for CNS hyperexcitability underlying the epileptic state. Because viral-mediated gene delivery can result in stable transduction of neurons with agents that have the potential to affect this imbalance, seizure disorders represent an attractive target for gene therapy. Thus far, therapeutic strategies have focused on the modulation of signaling, mediated by the main classic excitatory and inhibitory neurotransmitters, glutamate and $\gamma$-aminobutyric acid (GABA). However, over the past 20-year period, increasing attention has been focused on a group of bioactive peptides, including galanin and neuropeptide $Y$, which are abundantly expressed in the brain (7). As increased information has accumulated on the involvement of these peptides in fundamental physiologic and behavioral functions, such as feeding, anxiety, learning, memory, and attention, it has become clear that the peptides also can modulate neuronal excitability in a beneficial way to protect against seizures.

The preferential release of neuropeptides under conditions of increased neuronal activity, and in particular during seizures, has encouraged investigation of their role in seizure modulation (7). Both galanin (a 29- to 30-amino acid peptide) and neuropeptide $Y$ (a 36-amino acid polypeptide) have been shown to antagonize excitatory glutamatergic neurotransmission in the hippocampus (8-10). Compelling evidence supports an anticonvulsant role for these peptides in various experimental 
models of seizures, either when exogenously applied or when endogenously released (11-15). Neuroprotection against excitotoxic cell death $(26,17)$ and seizure-induced neurogenesis (18) are two novel aspects of peptide action in the CNS that are relevant to epilepsy research. These findings led to the hypothesis that augmentation of local inhibitory tone, resulting from overexpression of these two neuroactive peptides in specific brain areas, may be an effective strategy for inhibition of seizures and epileptogenesis. Attenuation of seizure and neuronal death by $A A V$ vectors that mediate galanin expression and secretion recently has been reported $(17,19)$.

$A A V$ vectors with different characteristics were designed to overexpress galanin constitutively in neurons. In one study, an AAV vector was engineered to carry a fibronectin sequence together with the galanin gene (17). AAV-mediated delivery of this secretory signal, along with the coding sequence for the active galanin peptide, significantly attenuated in vivo focal seizure sensitivity in rat inferior collicular cortex and prevented hippocampal hilar cell loss consequent to kainate-induced seizures. By adopting a doxycycline-sensitive rAAV vector, this elegant study showed that when doxycycline was added to drinking water, the threshold for seizure generation returned to baseline within 1 week. This study demonstrates the feasibility of both controllable and long-term ( $\leq 4$ weeks) seizure attenuation with a gene-therapy vector. In another study, Lin et al. (19) adopted an rAAV vector in which the galanin gene was driven by a neuron-specific promoter. The study showed long-lasting ( $\leq 2.5$ months) functional overexpression of galanin, specifically in hilar interneurons and their terminal projection fields, thus demonstrating that the peptide can be produced and transported along axons even a long distance from its site of synthesis. Lin and colleagues (19) reported that restricted galanin overexpression results in powerful inhibition of seizures induced by intrahippocampal injection of kainic acid, as detected on electroencephalogram (EEG).

Richichi et al. (20) studied the effect on acute kainateinduced seizures and kindling epileptogenesis of long-lasting neuropeptide $\mathrm{Y}$ overexpression by local application of recombinant AAV vectors in the rat hippocampus (20). The authors used vectors with different serotypes and clearly showed that tissue can be more efficiently targeted by varying capsid genes (21). rAAV serotype 2 (rAAV2) vector increased neuropeptide $\mathrm{Y}$ expression in hilar interneurons only, whereas the chimeric serotypes 1 and 2 vector caused far more widespread expression including mossy fibers, pyramidal cells, and subiculum (Fig. 1). Seizures detected by EEG, induced by intrahippocampal
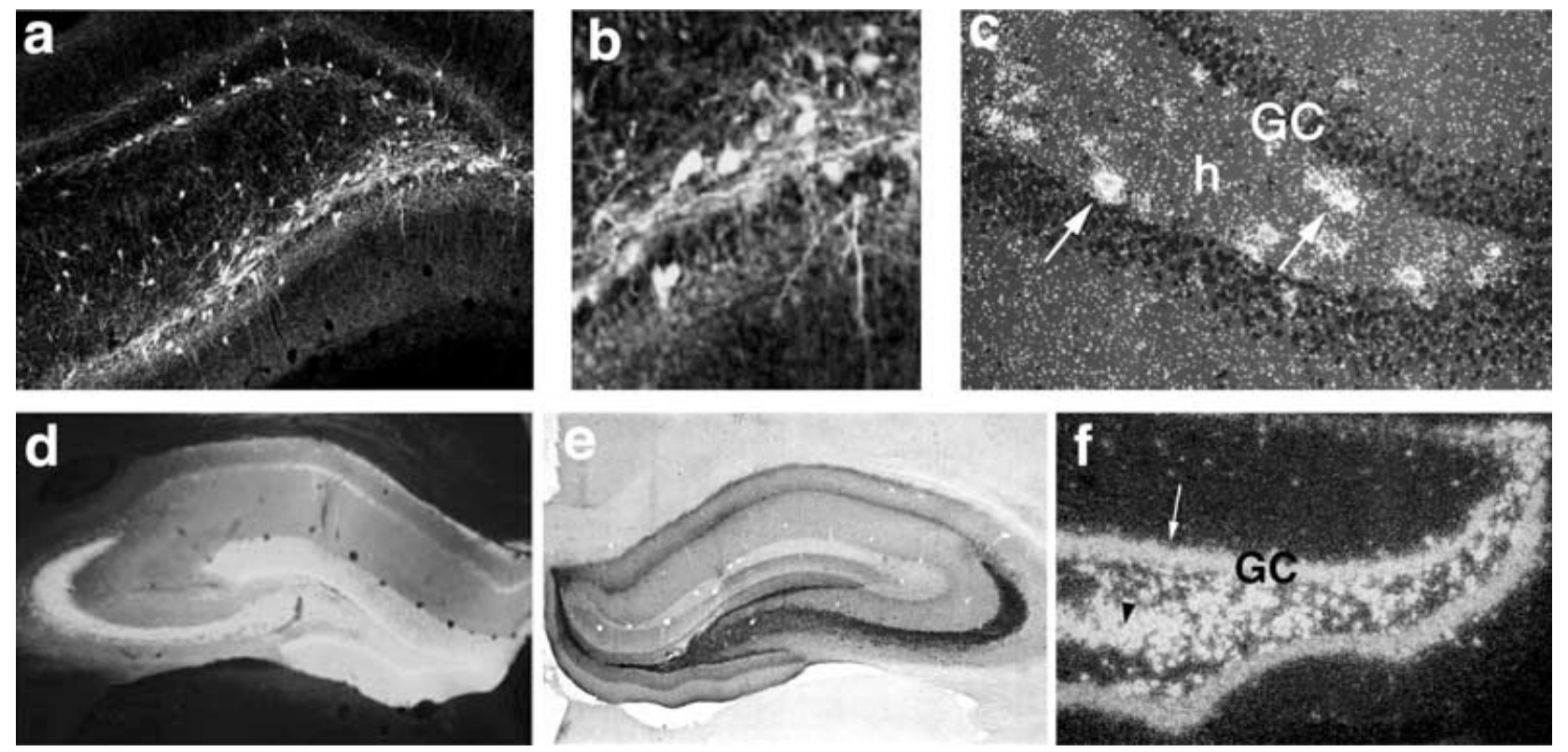

FIGURE 1 Expression of green fluorescent protein and neuropeptide $Y$ in the hippocampus of representative rats, injected 8 weeks previously with recombinant adeno-associated virus (rAAV) serotype 2 or chimeric serotypes 1 and 2. rAAV serotype-2 induces transgene expression specifically in hilar interneurons with a spread of $\sim 1.5 \mathrm{~mm}$ around the injection site. A, B: Green fluorescent protein in hilar interneurons and their fibers. C: Neuropeptide Y messenger RNA (mRNA) in hilar interneurons (arrows). Note that granule cells do not express the transgene. rAAV chimeric serotypes 1 and 2 induce a larger transgene expression, including hilar interneurons, mossy fibers, and granule cells, with an extension of $\sim 2.5 \mathrm{~mm}$ around the injection site. D: Green fluorescent protein distribution. E, F: Neuropeptide $\mathrm{Y}$ immunoreactivity and its mRNA, respectively. Note that intense hybridization signal is observed in granule cells (arrow in F) and CA3 (arrowhead in F). Transgenes were selectively expressed in neurons because they were under control of the neuronal enolase promoter. GC, granule cells; h, hilus. [From Richichi C, En-Ju D. Anticonvulsant and antiepileptogenic effects mediated by adeno-associated virus vector neuropeptide $Y$ expression in the rat hippocampus. J Neurosci (in press), with permission]. 
injection of kainate, were reduced by $50 \%$ to $75 \%$, depending on the spread of neuropeptide $Y$ expression, and seizure onset was markedly delayed. In rats injected with chimeric serotypes 1 and 2 vector, status epilepticus was abolished, and kindling acquisition was significantly delayed. The experimental findings in rodent models of seizures suggest that targeted gene transfer may provide a basis for development of new gene therapies that may be useful to treat drug-resistant focal seizure disorders.

Numerous studies have demonstrated that gene-therapy interventions can protect neurons from death after neurologic insults. By using a herpes simplex virus- 1 system to overexpress either the glucose transporter-1 (Glut-1) or the apoptosis inhibitor Bcl-2, McLaughlin et al. (22) showed that both genes were protective against kainate-induced hippocampal damage, when introduced either before or 1 hour after the excitotoxin. Thus neurons can be rescued even when targeting early-stage events that occur after the insult.

The main alternative to viral vectors for gene transfer into CNS cells is pegylated immunoliposomes that carry the plasmid DNA for expressing the exogenous gene. By using a brain cell-specific promoter and a targeting ligand that binds to a transporting receptor on the blood-brain barrier, it is possible to confine the expression of the exogenous gene to the brain. The advantage of this nonviral vector-delivery system is its systemic, and thus noninvasive, application (23). However, the persistence and level of expression of the transgene are limited compared with those of viral vector-mediated gene delivery.

\section{Cell Grafting}

A different approach to controlling seizures with the use of gene transfer involves brain grafting of cells that are engineered to release inhibitory neurotransmitters or neuroactive compounds $(24,25)$. For example, fibroblasts engineered to release adenosine have been encapsulated into semipermeable polymers and grafted into the brain ventricles of kindled rats (24). Adenosine, released locally from cell grafts, provides nearly complete protection from kindled seizures for a period of up to 24 days. The diminution of seizure protection appears to result from a decrease in viability of the engineered fibroblasts. The authors envisaged the use of embryonic stem cells as a future strategy to develop adenosine-releasing cells of different developmental lineages. For instance, adenosine-releasing myoblasts with a defined genetic origin might be generated and fused into myotubes that have been demonstrated to survive for at least 6 months after encapsulation and grafting (26).

Genetically engineered GABA-producing cells, obtained from immortalized mouse cortical neurons expressing the GABA-synthesizing enzyme GAD65, raised seizure threshold when transplanted into key epileptogenic nuclei in rats (25).
Transplantation approaches consisting of brain grafting of embryonic noradrenergic, serotonergic, or cholinergic neurons have been efficient in retarding seizure development induced by kindling stimulation, indicating the potential antiepileptogenic effects of differentiated neurons that express inhibitory substances (27-29).

Although substantial seizure suppression can be obtained with engineered cell grafting, the anticonvulsant effect is highly dependent on cell viability and is restricted to a few weeks in rodents. Thus alternate strategies for the engineering of cells with longer survival time must be developed. For example, it may be possible to introduce survival-enhancing genes.

The preliminary studies reported to date that show inhibitory effects on seizures and epileptogenesis and evidence for neuroprotection from seizure-mediated cell death provide optimism that transgene overexpression in the CNS could be a viable epilepsy treatment approach. The strategy is most likely to be effective in the treatment of focal-onset seizures, such as in temporal lobe epilepsy. However, further studies on gene transfer in spontaneously epileptic animals are mandatory to assess the clinical relevance of these early observations. The rapid advancement in recombinant viral-vector and cell-grafting technology provides exciting opportunities for studies in animal models, which are required before clinical trials. In the future, clinical-grade vectors stereotaxically delivered into the seizure focus could provide an alternative to resective surgery in the treatment of partial epilepsy.

\section{References}

1. Mountain A. Gene therapy: the first decade. Trends Biotechnol 2000;18:119-128.

2. Simonato M, Manservigi R, Marconi P, Glorioso J. Gene transfer into neurons for the molecular analysis of behaviour: Focus on herpes simplex vectors. Trends Neurosci 2000;23:183-189.

3. Ferrari F, Xiao X, McCarty D, Samulski RJ. New developments in the generation of Ad-free, high-titer rAAV gene therapy vectors. Nat Med 1997;3:1295-1297.

4. Janson CG, McPhee SWJ, Leone P, Freese A, During MJ. Viralbased gene transfer to the mammalian CNS for functional genomic studies. Trends Neurosci 2001;24:706-712.

5. Dong JY, Fan PD, Frizell RA. Quantitative analysis of the packaging capacity of recombinant adeno-associated virus. Hum Gene Ther 1996;7:2101-2112.

6. Donsante A, Vogler C, Muzyczka N, et al. Crawford JM, Barker J, Flotte T, Campbell-Thompson M, Daly T, Sands MS. Observed incidence of tumorigenesis in long-term rodent studies of rAAV vectors. Gene Ther 2001;8:1343-1346.

7. Hokfelt T. Neuropeptides in perspective: The last ten years. Neuron 1991;7:867-879.

8. Colmers WF, Lukowiak K, Pittman QJ. Presynaptic action of neuropeptide $\mathrm{Y}$ in area $\mathrm{CA} 1$ of the rat hippocampal slice. J Physiol 1987;383:285-299.

9. Greber S, Schwarzer C, Sperk G. Neuropeptide Y inhibits potassium-stimulated glutamate release through $\mathrm{Y} 2$ receptors in 
rat hippocampal slices in vitro. Br J Pharmacol 1994;113:737740.

10. Zini S, Roisin MP, Langel U, Bartfai T, Ben-Ari Y. Galanin reduces release of endogenous excitatory amino acids in the rat hippocampus. Eur J Pharmacol 1993;245:1-7.

11. Mazarati A, Langel U, Bartfai T. Galanin: An endogenous anticonvulsant? Neuroscientist 2001;7:506-517.

12. Mazarati A, Wasterlain CG. Anticonvulsant effects of four neuropeptides in the rat hippocampus during self-sustaining status epilepticus. Neurosci Lett 2002;331:123-127.

13. Kokaia M, Holmberg K, Nanobashvili A, Xu ZQ, Kokaia Z, Lendahl U, Hilke S, Theodorsson E, Kahl U, Bartfai T, Lindvall $\mathrm{O}$, Hokfelt T. Suppressed kindling epileptogenesis in mice with ectopic overexpression of galanin. Proc Natl Acad Sci U S A 2001;98:14006-14011.

14. Vezzani A, Sperk G, Colmers WF. Neuropeptide Y: Emerging evidence for a functional role in seizure modulation. Trends Neurosci 1999;22:25-30.

15. Vezzani A, Michalkiewicz M, Michalkiewicz T, Moneta D, Ravizza T, Richichi C, Aliprandi M, Mule F, Pirona L, Gobbi M, Schwarzer C, Sperk G. Seizure susceptibility and epileptogenesis are decreased in transgenic rats overexpressing neuropeptide Y. Neuroscience 2002;110:237-243.

16. Silva AP, Pinheiro PS, Carvalho AP, Carvalho CM, Jakobsen B, Zimmer J, Malva JO. Activation of neuropeptide Y receptors is neuroprotective against excitotoxicity in organotypic hippocampal slice cultures. FASEB J 2003;17:1118-1120.

17. Haberman RP, Samulski RJ, McCown TJ. Attenuation of seizures and neuronal death by adeno-associated virus vector galanin expression and secretion. Nat Med 2003;9:1076-1080.

18. Howell OW, Scharfman HE, Herzog H, Sundstrom LE, BeckSickinger A, Gray WP. Neuropeptide Y is neuroproliferative for post-natal hippocampal precursor cells. J Neurochem 2003;86:646-659.

19. Lin ED, Richichi C, Young D, Baer K, Vezzani A, During MJ. Recombinant AAV-mediated expression of galanin in rat hippocampus suppresses seizure development. Eur J Neurosci 2003;18:1-6.

20. Richichi C, Lin ED, Stefanin D, Colella D, Ravizza T, Grignaschi G, Veglianese P, Sperk G, During MJ, Vezzani A. Anticonvulsant and antiepileptogenic effects mediated by adeno-associated virus vector neuropeptide $\mathrm{Y}$ expression in the rat hippocampus. J Neurosci 2004 (in press).

21. Davidson BL, Stein CS, Heth JA, Martins I, Kotin RM, Derksen TA, Zabner J, Ghodsi A, Chiorini JA. Recombinant adenoassociated virus type 2, 4, and 5 vectors: transduction of variant cell types and regions in the mammalian central nervous system. Proc Natl Acad Sci U S A 2000;97:3428-3432.

22. McLaughlin J, Roozendaal B, Dumas T, Gupta A, Ajilore O, Hsieh J, Ho D, Lawrence M, McGaugh JL, Sapolsky R. Sparing of neuronal function postseizure with gene therapy. Proc Natl Acad Sci U S A 2000;97:12804-12809.

23. Shi N, Pardridge WM. Noninvasive gene targeting to the brain. Proc Natl Acad Sci U S A 2000;97:7567-7572.

24. Huber A, Padrun V, Deglon N, Aebischer P, Mohler H, Boison D. Grafts of adenosine-releasing cells suppress seizures in kindling epilepsy. Proc Natl Acad Sci U S A 2001;98:7611-7616.

25. Gernert M, Thompson KW, Loscher W, Tobin AJ. Genetically engineered GABA-producing cells demonstrate anticonvulsant effects and long-term transgene expression when transplanted into the central piriform cortex of rats. Exp Neurol 2002;176:183192.

26. Déglon N, Heyd B, Tan SA, Joseph JM, Zurn AD, Aebischer $P$. Central nervous system delivery of recombinant ciliary neurotrophic factor by polymer encapsulated differentiated $\mathrm{C} 2 \mathrm{C} 12$ myoblasts. Hum Gene Ther 1996;7:2135-2146.

27. Clough R, Statnick M, Maring-Smith M, Wang C, Eells J, Browning R, Dailey J, Jobe P. Fetal raphe transplants reduce seizure severity in serotonin-depleted GEPRs. Neuroreport 1996;8:341-346.

28. Ferencz I, Kokaia M, Elmer E, Keep M, Kokaia Z, Lindvall O. Suppression of kindling epileptogenesis in rats by intrahippocampal cholinergic grafts. Eur J Neurosci 1998;10:213-220.

29. Kokaia M, Cenci MA, Elmer E, Nilsson OG, Kokaia Z, Bengzon J, Bjorklund A, Lindvall O. Seizure development and noradrenaline release in kindling epilepsy after noradrenergic reinnervation of the subcortically deafferented hippocampus by superior cervical ganglion or fetal locus coeruleus grafts. Exp Neurol 1994; 130:351-361. 